\title{
Aortic root remodeling: Ten-year experience with 274 patients
}

Diana Aicher, MD, Frank Langer, MD, Henning Lausberg, MD, Benjamin Bierbach, MD, and Hans-Joachim Schäfers, MD

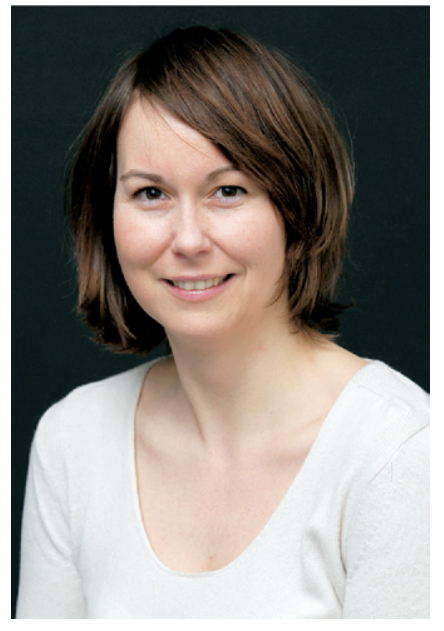

Dr Aicher

Earn CME credits at http://cme.ctsnetjournals.org
Objectives: Dilatation of the aortic root with concomitant aortic regurgitation can be treated by valve-preserving surgery. We have consistently chosen root remodeling rather than reimplantation whenever the aortoventricular junction was not dilated. We have analyzed our 11-year experience with root remodeling.

Methods: Between October 1995 and October 2006, 274 patients (201 male; 73 female, aged $59 \pm 15$ years) were treated by root remodeling in the presence of a preserved aortoventricular diameter $(<30 \mathrm{~mm})$. Acute aortic dissection was present in 46 patients. The valve anatomy was tricuspid in 193 and bicuspid in 81 patients. Cusp disease was additionally corrected in 173 (63\%) patients. Follow-up was complete in $99 \%$. Cumulative follow-up was 1045 patient-years (mean of $4.0 \pm 2.7$ years).

Results: Hospital mortality was 3.6\% (elective 3.1\%; emergency 6.5\%). One patient had endocarditis 2 months postoperatively and subsequently underwent valve replacement. Freedom from aortic regurgitation of grade II or more was $91 \%$ and $87 \%$ at 10 years for bicuspid and tricuspid aortic valves. Nine patients required reoperation: in 6 patients the valve was replaced and in 3 patients rerepaired. Freedom from reoperation was $96 \%$ at 5 and 10 years, and freedom from valve replacement was $98 \%$ at 5 and 10 years. A comparison of 3 operative periods (1995-1998, 19992002, and 2003-2006) showed that with increasing experience cusp prolapse was diagnosed and corrected more frequently $(8 / 49=17 \% ; 62 / 105=59 \% ; 103 / 108=$ $82 \% ; P<.0001)$, and repair stability significantly improved over time $(P=.007)$.

Conclusions: Root remodeling leads to durable restoration of aortic valve function in both tricuspid and bicuspid valve anatomy. Aggressive correction of cusp prolapse seems to have a beneficial effect on aortic valve competence.

$\mathrm{D}$ ilatation of the aortic root currently is the most common mechanism leading to aortic regurgitation. ${ }^{1}$ Once diameters of 5 to $5.5 \mathrm{~cm}$ are exceeded, surgery has to address both aortic dilatation and aortic valve regurgitation, From the Department of Thoracic and Cardiovascular Surgery, University Hospital of Saarland, Homburg/Saar, Germany.

Received for publication Feb 4, 2007; revisions received April 10, 2007; accepted for publication May 11, 2007.

Address for reprints: Prof Dr H.-J. Schäfers, Department of Thoracic and Cardiovascular Surgery, University Hospital of Saarland, 66421 Homburg/Saar, Germany (E-mail: h-j.schaefers@uniklinikum-saarland.de).

J Thorac Cardiovasc Surg 2007;134:909-15 0022-5223/\$32.00

Copyright (C) 2007 by The American Association for Thoracic Surgery

doi:10.1016/j.jtcvs.2007.05.052 commonly by composite replacement. ${ }^{2}$ Valve-preserving surgery has become an established alternative for these patients. In addition, aortic replacement may also be useful as a means of stabilizing the aortic root in the context of aortic valve repair.

Currently, there are essentially two different techniques of valve-preserving aortic replacement. Remodeling of the aortic root was published by Sarsam and Yacoub $^{3}$ in 1993 and reimplantation of the aortic valve in a vascular graft was proposed by David and Feindel ${ }^{4}$ in 1992. Although different modifications have been proposed for each approach, the underlying principle has remained the same. Root remodeling recreates the normal configuration of aortic sinuses and the sinotutoventricular junction. There is an ongoing controversy over the shape of the neosinuses and their functional implications on cusp motion. ${ }^{5,6}$ Both techniques were initially designed for patients with tricuspid aortic valves (TAV) and normal bular junction. Valve reimplantation additionally reduces and stabilizes the aor- 


\section{Abbreviations and Acronyms \\ $\mathrm{BAV}=$ bicuspid aortic valve \\ TAV $=$ tricuspid aortic valve}

or minimally altered aortic leaflets. With increasing experience, the indication was extendend to patients with bicupid aortic valve (BAV) disease $e^{7,8}$ and additional pathologic conditions of the leaflets. ${ }^{8,9}$

Similar to mitral valve repair, both techniques are intended to minimize the incidence of valve-related complications compared with replacement. However, there are few data on the long-term results of both forms of valvepreserving aortic replacement. The relative role of root remodeling versus valve reimplantation has been discussed, albeit controversially.

We have performed root remodeling for more than 10 years in all patients with aortic root aneurysms in the presence of a normal aortoventricular diameter. In this retrospective analysis, we tested the hypothesis that remodeling leads to durable restoration of aortic valve function in TAV and BAV.

\section{Patients and Methods}

Between October 1995 and October 2006, 399 patients with dilatation of the ascending aorta and aortic valve regurgitation were operated on in our institution. Root remodeling was chosen as the operative strategy $(n=274)$ whenever the sinuses and sinotubular junction were enlarged and the aortoventricular junction preserved $(<30 \mathrm{~mm})$. Intraoperative measurements under cardioplegia were taken as the basis for deciding on the operative strategy, and all of these patients had a sinotubular diameter of more than $32 \mathrm{~mm}$, corresponding to transesophageal echocardiography measurements of approximately $40 \mathrm{~mm}$.

In patients with a sinotubular junction of $32 \mathrm{~mm}$ or smaller and supracommissural aortic dilatation, the proximal aorta was replaced and the valve was addressed separately if necessary $(\mathrm{n}=$ 99). If the aortoventricular junction exceeded $30 \mathrm{~mm}$ or connective tissue disease was present, the valve was reimplanted within a vascular graft $(\mathrm{n}=26)$.

The 274 patients (201 male; 73 female; aged $59 \pm 15$ years) who were treated by remodeling were the subject of this retrospective study. The investigation was approved by the local ethics committee, and the need for individual patient consent was waived for this analysis.

The primary indication for the operation was aortic regurgitation in 93 patients and ascending aortic aneurysm in 135 patients. Forty-six patients were operated on under emergency conditions for type A dissection. Valve anatomy was bicuspid in 81 and tricuspid in 193 patients. Maximum aortic diameters and degree of preoperative aortic regurgitation are summarized in Table 1. Five patients had Marfan syndrome. Concomitant diseases were coronary artery disease $(n=62)$, mitral valve regurgitation $(n=10)$, and aortic arch aneurysm $(n=128)$ (Table 1$)$.
TABLE 1. Clinical data of 274 patients after root remodeling in the presence of bicuspid or tricuspid aortic valve anatomy

\begin{tabular}{lccc}
\hline & BAV & TAV & \\
& $(\mathbf{n}=\mathbf{8 1})$ & $(\mathbf{n}=\mathbf{1 9 3})$ & $\boldsymbol{P}$ value \\
\hline Age (y) & $52 \pm 12$ & $62 \pm 15$ & $<.001$ \\
Gender (M/F) & $69 / 12$ & $132 / 61$ & .004 \\
AADA (n) & 6 & 40 & .007 \\
Previous cardiac surgery (n) & 0 & 7 & .11 \\
Marfan (n) & 0 & 5 & .33 \\
Preoperative degree of AR & & & \\
I & 20 & 51 & .88 \\
II & 16 & 48 & .44 \\
III & 37 & 79 & .50 \\
$\quad$ IV & 8 & 15 & .63 \\
Maximum diameter of the & $55 \pm 6$ & $60 \pm 11$ & .015 \\
$\quad$ ascending aorta (mm) & & & \\
Coronary artery disease (n) & 9 & 53 & .0026 \\
Mitral regurgitation $(\mathrm{n})$ & 1 & 9 & .29 \\
Aortic arch aneurysm (n) & 16 & 112 & $<.001$ \\
\hline BAV Bicuspid & &
\end{tabular}

$B A V$, Bicuspid aortic valve; $T A V$, tricuspid aortic valve; $A A D A$, acute aortic dissection type $\mathrm{A} ; A R$, aortic regurgitation.

The decision for the operative strategy was based on the preoperative aortogram showing the configuration of the aortic root and echocardiography, when the direction of the regurgitant jet indicated cusp prolapse.

\section{Operative Technique}

In all patients the chest was opened by a median sternotomy and the patient supported by extracorporeal circulation with aortic and right atrial cannulation. In acute dissection the right femoral $(\mathrm{n}=$ $25)$ or right axillary artery $(n=21)$ was used for arterial cannulation. Cardioplegic arrest was induced by infusion of blood cardioplegic solution into the coronary ostia. The aortic root was inspected, and diameters of the aortoventricular junction and sinotubular junction were measured with graded valve sizers. The aorta was completely transected 5 to $10 \mathrm{~mm}$ above the commissures. Stay sutures were placed, and the aortic root was mobilized down to the lowest point of the sinuses. The graft size was always chosen 1 to $2 \mathrm{~mm}$ smaller than the aortoventricular diameter. In TAV anatomy, the graft was tailored to create three symmetric neosinuses. The sinuses were excised and the root replaced with the graft, thus re-establishing a normal configuration. If the valve was bicuspid, the aortic sinuses were similarly excised. In the presence of a symmetric BAV $(n=2)$, symmetric root geometry was also present. In 79 instances, congenital fusion between the right and left coronary cusps was found and the root showed the typical asymmetry with a large noncoronary sinus and two rudimentary sinuses. In those patients, the Dacron graft was tailored to accommodate the individual geometry of the root. The coronary ostia were implanted into the graft in standard fashion.

Once the graft had been sutured in place, the aortic valve was inspected carefully for additional cusp disease. Prolapse was initially defined as a difference in the height of a free margin relative to the other margins of $2 \mathrm{~mm}$ or more. In the past 2 years $(\mathrm{n}=71)$, 
we have measured to the height difference between the central free margin and the lowest point of the aortic insertion line in the respective sinus ("effective height"). Using a caliper for direct measurement of this parameter, we have changed the definition of prolapse to an effective height of the free cusp margin of 2 to $3 \mathrm{~mm}$ less than predicted. ${ }^{10}$

Prolapse was corrected according to our standard procedures. ${ }^{11}$ In most instances, central plication of the free margin $(n=162)$ was done with 5-0 or 6-0 Prolene sutures (Ethicon, Inc, Somerville, NJ). One to five stitches were placed until adequate cusp height was achieved. In case of limited calcified or fibrotic tissue, a triangular resection of cusp tissue was performed $(n=38)$. In the presence of fenestrations or cusp defects after resection of limited calcifications, we used autologous pericardium for cusp reconstruction $(\mathrm{n}=5)$.

Additional coronary artery bypass grafting was performed in 62 patients and mitral valve repair in 10 patients. The replacement of the $\operatorname{arch}(n=128$; partial $n=107$; total $n=21)$ was performed under hypothermic circulatory arrest $\left(18^{\circ} \mathrm{C}-21^{\circ} \mathrm{C}\right.$ nasopharyngeal temperature).

\section{Echocardiographic Analysis}

Intraoperative transesophageal echocardiography (HDI 3000; ATL Technologies, Hagen, Germany) was performed after weaning from cardiopulmonary bypass with a diastolic blood pressure of 70 $\mathrm{mm} \mathrm{Hg}$. A semiquantitative assessment of the degree of aortic regurgitation was performed with continuous-wave Doppler using the intensity and slope of the regurgitation signal. ${ }^{12}$ In addition, the width of the regurgitation jet in relation to the diameter of the left ventricular outflow tract was measured by color Doppler. ${ }^{12}$ In this instance, there was almost normal configuration of the aortic valve without exceeding trivial aortic regurgitation. Postoperatively, transthoracic echocardiography was performed for determination of aortic regurgitation and systolic gradients at 1 week, 6 and 12 months, and every 12 months thereafter. Follow-up was complete in $99 \%$. Cumulative follow-up was 1045 patient-years with a mean of $4.0 \pm 2.7$ years.

\section{Statistical Analysis}

Continuous data are expressed as mean \pm standard deviation and analyzed by the Mann-Whitney $U$ test. Categorical variables are described by contingency tables and analyzed by the $\chi^{2}$ test. Kaplan-Meier estimates of actuarial freedom from reoperation and degree of aortic regurgitation as well as corresponding $95 \%$ confidence intervals were calculated with a commercially available software package (Prism; GraphPad Inc, San Diego, Calif). Comparison of the curves was done by the log-rank test.

\section{Results}

Patients with BAV were younger $(P<.001)$ (Table 1$)$ and more often required additional correction of cusp pathologic conditions $(P<.001)$. The technique of cusp repair also differed between the two valve morphologic types. Pericardial patches were used with equal frequency, whereas more plication and triangular resections were performed in BAV. In BAV anatomy there was less need for arch replacement $(P<.001)$ and concomitant coronary artery bypass grafting
TABLE 2. Intraoperative data of 274 patients after root remodeling in the presence of bicuspid or tricuspid aortic valve anatomy

\begin{tabular}{|c|c|c|c|}
\hline & $\begin{array}{c}\text { BAV } \\
(n=81)\end{array}$ & $\begin{array}{c}\text { TAV } \\
(n=193)\end{array}$ & $P$ value \\
\hline ST diameter (mm) & $39 \pm 6$ & $40 \pm 6$ & .37 \\
\hline AV diameter (mm) & $28 \pm 2$ & $26 \pm 2$ & $<.001$ \\
\hline Prothesis size $(\mathrm{mm})$ & $25.5 \pm 1.0$ & $24.7 \pm 1.4$ & $<.001$ \\
\hline Prolapse correction (n) & 70 & 103 & $<.001$ \\
\hline One cusp & 28 & 53 & \\
\hline Two cusps & 42 & 29 & \\
\hline Three cusps & & 21 & \\
\hline \multicolumn{4}{|l|}{ Prolapse correction (method) } \\
\hline Plication & 60 & 102 & .007 \\
\hline Triangular resection & 36 & 2 & $<.001$ \\
\hline Pericardial patch & 1 & 4 & .65 \\
\hline \multicolumn{4}{|l|}{ Arch replacement $(\mathrm{n})$} \\
\hline Partial & 16 & 91 & $<.001$ \\
\hline Total & 0 & 21 & .0007 \\
\hline Mitral valve repair (n) & 1 & 9 & .29 \\
\hline CABG (n) & 9 & 53 & .0026 \\
\hline CPB time (min) & $105 \pm 29$ & $127 \pm 44$ & $<.001$ \\
\hline Aortic crossclamp time (min) & $78 \pm 13$ & $88 \pm 21$ & $<.001$ \\
\hline
\end{tabular}

$B A V$, Bicuspid aortic valve; $T A V$, tricuspid aortic valve; $S T$, sinotubular; $A V$, aortoventricular diameter; $C A B G$, coronary artery bypass grafting; $C P B$, cardiopulmonary bypass.

$(P=.026)$; consequently, extracorporeal circulation $(P<$ $.001)$, myocardial ischemic $(P<.001)$, and circulatory arrest times $(P<.001)$ were shorter (Table 2$)$.

Hospital mortality was $3.6 \%$ (10/274; elective surgery, $7 / 228=3.1 \%$; emergency surgery, $3 / 46=6.5 \%)$. No patient died after repair of a BAV, whereas 10 patients died after TAV repair. The causes of death were mesenteric ischemia and multiple organ failure $(n=6)$, cerebral ischemia $(\mathrm{n}=1)$, pulmonary embolism $(\mathrm{n}=1)$, and left ventricular failure $(n=2)$. Hospital mortality for patients who had remodeling without need for an additional surgical procedure was $1.4 \%(2 / 142)$.

Thirteen patients required re-exploration for bleeding $(13 / 274=4.7 \%)$. Neurologic complications were observed in 3 patients after emergency surgery (paraparesis, $n=2$; cerebral infarction, $\mathrm{n}=1$ ). Another patient had a prolonged reversible ischemic neurologic deficit after elective surgery. There was no episode of postoperative atrioventricular block. Throughout the follow-up period, no episode of thromboembolism was observed.

Survival at 5 and 10 years was $91 \%$ and $87 \%(100 \%$ and $94 \%$ for BAV; $87 \%$ and $83 \%$ for TAV; $P=.006$; Figure 1$)$. Ten patients (BAV, $\mathrm{n}=1 ; \mathrm{TAV}, \mathrm{n}=9$ ) died during follow-up. Causes of death were sudden death in 2 patients 6 and 7 years after the operation, myocardial infarction in 2 patients, pneumonia in 2 patients, cancer in 2 patients, and renal failure in 1 patient. One patient required repeat coro- 


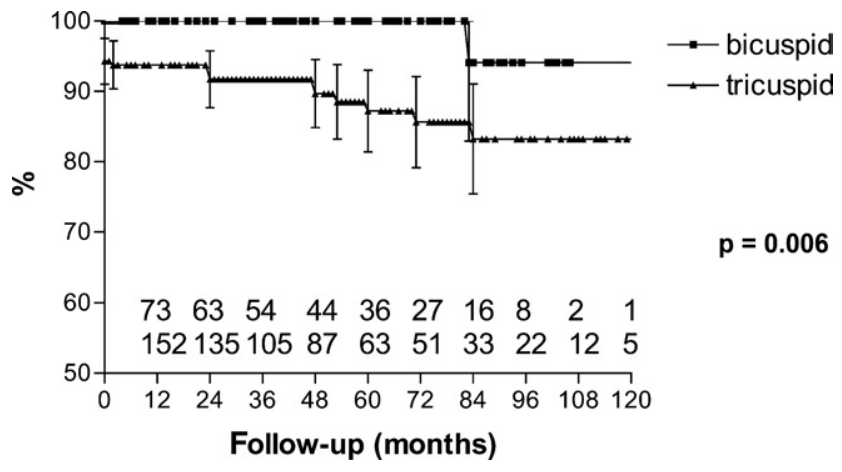

Figure 1. Actuarial survival of patients after remodeling analyzed by bicuspid and tricuspid valve anatomy including subjects at risk (bottom) and $95 \%$ confidence intervals $(P=.006)$.

nary revascularization and died postoperatively of mesenteric ischemia.

Freedom from aortic regurgitation of grade II or more was $96 \%$ at 5 and 10 years for BAV and $88 \%$ at 5 years and $87 \%$ at 10 years for TAV $(P=.08$; Figure 2$)$. Nine patients required reoperation $(\mathrm{BAV}, \mathrm{n}=2 ; \mathrm{TAV}, \mathrm{n}=7$ ) (Table 3 ). In most patients ( $\mathrm{n}=6$; $\mathrm{BAV}, \mathrm{n}=2 ; \mathrm{TAV}, \mathrm{n}=4)$, symmetric cusp prolapse with low effective height was found. Other reasons for reoperation were dilatation at the aortoventricular level (TAV, $\mathrm{n}=1$ ), endocarditis (TAV, $\mathrm{n}=1)$, and secondary cusp retraction $(\mathrm{TAV}, \mathrm{n}=1)$.

Freedom from reoperation was $97 \%$ at 5 and 10 years for $\mathrm{BAV}$ and $95 \%$ at 5 and 10 years for TAV $(P=.51$; Figure 3$)$. In 6 patients the valve was replaced and in 3 patients rerepaired $(\mathrm{BAV}, \mathrm{n}=1 ; \mathrm{TAV}, \mathrm{n}=2)$. Freedom from valve replacement was $99 \%$ at 5 and 10 years for BAV and $97 \%$ at 5 and 10 years for TAV $(P=.41$; Figure 4$)$.

Aortic valve function remained stable in most patients. Of the 9 patients who underwent reoperation, 6 had aortic

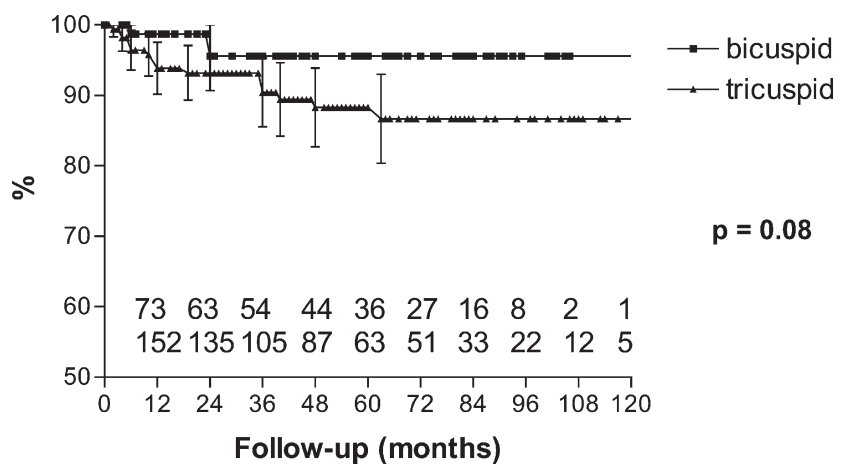

Figure 2. Actuarial freedom from aortic regurgitation of grade II or more of patients after remodeling analyzed by bicuspid and tricuspid valve anatomy including subjects at risk (bottom) and 95\% confidence intervals $(P=.08)$.
TABLE 3. Reasons for reoperation after root remodeling, stratified for aortic valve anatomy

\begin{tabular}{lcc}
\hline Reasons for reoperation & BAV & TAV \\
\hline Symmetric cusp prolapse & 2 & 4 \\
Dilatation at the aortoventricular level & 0 & 1 \\
Endocarditis & 0 & 1 \\
Secondary cusp retraction & 0 & 1 \\
\hline
\end{tabular}

$B A V$, Bicuspid aortic valve; TAV, Tricuspid aortic valve.

insufficiency grade I-II at discharge and showed progression of aortic regurgitation over time. There was some progression of aortic regurgitation to a maximum of less than grade III (left ventricular end-diastolic dimension $<63 \mathrm{~mm}$ ) in 11 other patients. Valve function has remained constant in all other patients.

A comparison of 3 operative periods (1995-1998, 1999 2002, and 2003-2006) showed that with increasing experience cusp prolapse was diagnosed and corrected more frequently $(8 / 49=17 \% ; 62 / 105=59 \% ; 103 / 120=86 \% ; P<$ $.0001)$, whereas valve stability significantly improved over time $(P=.007$; Figure 5$)$.

\section{Discussion}

Aortic dilatation either as a dilative form of atherosclerosis or a consequence of connective tissue disease leads to aortic regurgitation. ${ }^{1}$ Surgery may be required to address the aorta to eliminate the risk of dissection or rupture. The aortic valve should be preserved and, if necessary, functionally restored. In other patients, severe aortic valve regurgitation may lead to typical consequences of left ventricular overload and be the primary indication for surgery.

Acute aortic dissection in many instances occurs in preexistent aortic dilatation. Whereas root dissection can be managed by commissural resuspension and supracommissural replacement, pre-existent dilatation requires replace-

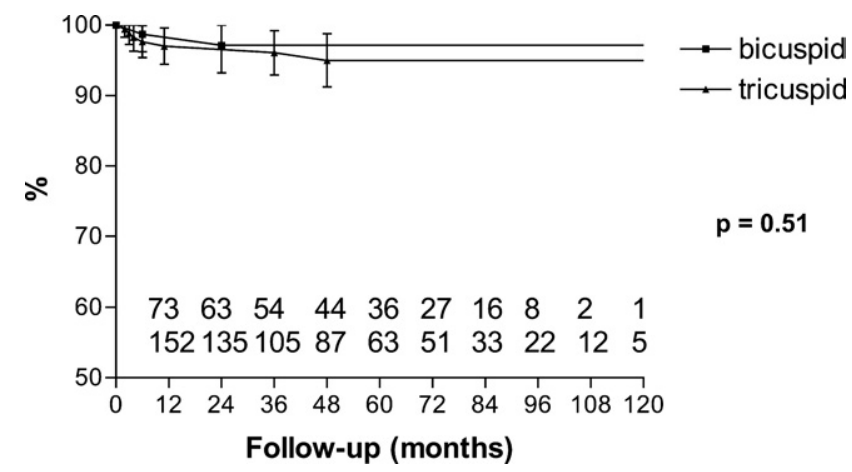

Figure 3. Actuarial freedom from reoperation of patients after remodeling analyzed by bicuspid and tricuspid valve anatomy including subjects at risk (bottom) and $95 \%$ confidence intervals $(P=$.51). 


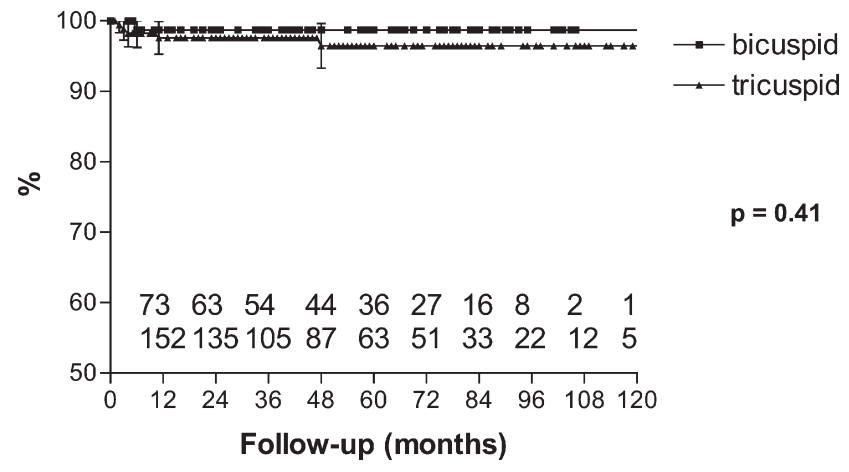

Figure 4. Actuarial freedom from valve replacement of patients after remodeling analyzed by bicuspid and tricuspid valve anatomy including subjects at risk (bottom) and $95 \%$ confidence intervals $(\boldsymbol{P}=.41)$.

ment of the root to provide a stable long-term solution. Aortic root replacement in this situation serves the purpose of normalizing root dimensions, thus stabilizing aortic valve repair similar to the function of a prosthetic ring in mitral valve repair.

Essentially two forms of valve-preserving root replacement exist. Root remodeling was originally designed and published by Sarsam and Yacoub. ${ }^{3}$ Its basic concept is to eliminate pathologic dilatation of the root and thus restore aortic valve function. The technique of reimplanting the aortic valve within a vascular graft was developed by David and Feindel. ${ }^{4}$ Reimplantation corrects annular ectasia as well as dilatation of the sinotubular junction. The relative role of these operative principles has been the subject of controversial discussion. Variable success rates of root remodeling with respect to valve stability have been reported. Luciani and associates ${ }^{13}$ showed early restoration of valve competence after remodeling. However, in a high proportion of patients (37\%), recurrence of severe aortic regurgitation with the need for reoperation was described within the first 2 years after operation. Annuloaortic ectasia was identified as one of the risk factors for reoperation. Similar results were reported from Leyh and colleagues, ${ }^{14}$ who found a high failure rate of aortic root remodeling in patients with acute type A dissection with a rate of reoperation of 37\% within 2 years. The reason for recurrent aortic regurgitation in all cases was prolapsing cusps. In contrast to those results, El Khoury and coworkers ${ }^{15}$ found good early results with the remodeling technique with only 1 reoperation in 45 patients at a follow-up of 30 months. The reason for reoperation was cusp repair failure. Yacoub and associates ${ }^{16}$ reported good long-term results in their series of 158 patients, with a freedom from reoperation at 1,5 , and 10 years of $97 \%, 89 \%$, and $89 \%$. An advantage of remodeling seems to be that aortic cusp motion has been found to be more physiologic in remodeling compared with reimplantation in clinical investigation, ${ }^{17}$ which was also confirmed by in vitro studies. ${ }^{18}$

Valve reimplantation has resulted in good valve stability in several series. ${ }^{19}$ In patients with Marfan syndrome, both types of valve-sparing operations provide similar results with regard to valve stability ${ }^{20,21}$; however, it was shown that reimplantation provides better stabilization of the aortoventricular junction. ${ }^{20}$ The less physiologic motion pattern of the cusps has not yet been proven to result in impairment of valve function up to 10 years postoperatively. In a recent comparison, reimplantation seemed to markedly exceed remodeling in 10-year freedom from recurrent aortic valve regurgitation. ${ }^{19}$

Compared with the reimplantation procedure, remodeling in our hands has the advantages of being less complex and time consuming. Ischemic times were limited to $76 \pm$ 10 minutes in patients who had remodeling without any additional surgical intervention. Ischemic times reported for reimplantation differed between $115 \pm 27$ minutes $^{19}$ and $132 \pm 33$ minutes. ${ }^{22}$ Mortality and morbidity were low in elective as well as in emergency cases in our series. One patient had acute endocarditis 3 months postoperatively and

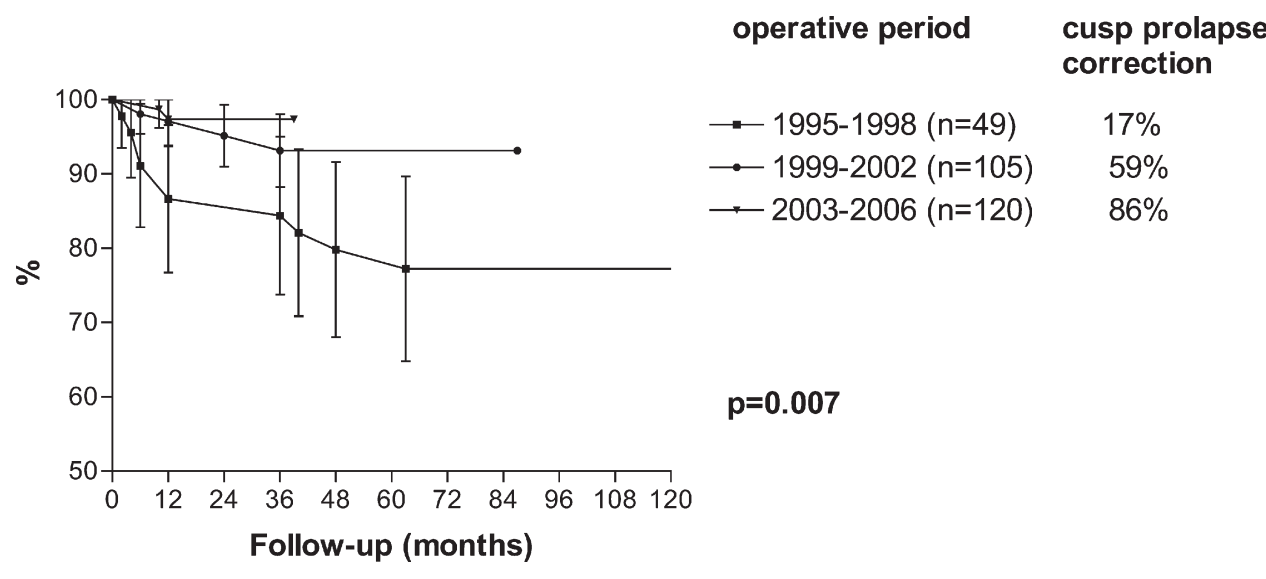

Figure 5. Actuarial freedom from aortic regurgitation of grade II or more of patients after remodeling analyzed by 3 different operative periods (1995-1998, 19992002, and 2003-2006) including subjects at risk (bottom) and $95 \%$ confidence intervals $(P=$ .007). 
was reoperated on for valve replacement, resulting in a linearized risk of endocarditis of $0.1 \%$ per patient-year.

In our series the reason for reoperation was mostly related to cusp prolapse, despite the fact that correction of prolapse was added to remodeling in 1998. This indicates that better detection of prolapse might have improved results even further. Prolapse may be predominant, as it is known that dimensions of the cusps may change with aortic root dilatation, ${ }^{23}$ or prolapse may be induced by reducing the sinotubular junction intraoperatively. Since we could identify cusp prolapse as a reason for failure after remodeling in several of our patients, one may have the impression that this is related to the type of root procedure, that is, root remodeling. On the other hand, abnormal cusp configuration has been identified as a risk factor for failure after aortic valve reimplantation, ${ }^{24}$ and indeed prolapse was identified in some of those patients at the time of reoperation when performed by the current senior author (H.-J.S). Thus, the possibility of inducing prolapse seems to be present for both forms of valve preservation.

The fact that prolapse was aggressively corrected appears to be the key for the good results obtained in our experience. Until recently, detection of prolapse was largely subjective. We have found in the past 2 years that determination of effective height of aortic cusps has been helpful in detecting prolapse intraoperatively. Our specially designed caliper allows reproducible measurement of this height difference in millimeters and aids in the determination of the extent of prolapse correction. ${ }^{10}$

Another possible difference between our strategy and that of other groups may be the fact that patients with dilated aortoventricular junction were excluded from root remodeling. It has been apparent that valve reimplantation is the only operative approach to reduce the size of a dilated aortoventricular junction, which is seen in typical annuloaortic ectasia or Marfan syndrome. ${ }^{20}$ Remodeling does not approach this part of the aortic root, and we have therefore avoided the application of remodeling in this pathologic condition. In those 5 patients with Marfan syndrome in whom we preferred remodeling instead of reimplantation, the aortoventricular diameter was smaller than $30 \mathrm{~mm}$ at the time of the operation. The longest follow-up in these patients is 33 months, and the aortoventricular diameters have remained constant.

We thus conclude that root remodeling can be applied with low morbidity and mortality in patients with root dilatation but preserved aortoventricular dimensions. Cusp prolapse is frequent and should be aggressively searched for and corrected. Long-term stability of aortic valve function under these circumstances is excellent for both BAV and TAV anatomy, and the risk of reoperation is low. Owing to its limited complexity, root remodeling is a good option in patients with aortic dilatation and aortic regurgitation undergoing valve-preserving aortic replacement.

\section{Limitations}

The major limitation of the current investigation is the retrospective approach to the analysis of long-term data. From a scientific standpoint, a prospective randomized trial comparing remodeling and reimplantation would be preferable. We have used our root technique according to our standardized indications. ${ }^{11}$ Thus, the majority of patients were treated by the remodeling technique. Reimplantation was reserved for patients with annuloaortic ectasia or connective tissue disease (eg, Marfan syndrome). Thus, the proportion of patients with Marfan syndrome in our remodeling series is relatively low in contrast to other series. ${ }^{19}$ However, we observed a high proportion of BAV anatomy in conjunction with dilated aortic roots.

Another limitation of our current investigation is the change of technical aspects over the years with a growing proportion of additional aortic cusp repairs, which we consider to be an important aspect of our results. Evaluation of aortic cusp prolapse, however, is challenging and requires a high level of expertise. We have tried to transform this surgical judgment into measurable parameters. In doing so, we have developed a parameter (effective height) and tool (caliper) to support the measurements obtained by transesophageal echocardiography and geometric measurements in the arrested heart.

\section{References}

1. Roman MJ, Devereux RB, Niles NW, Hochreiter C, Kligfield P, Sato $\mathrm{N}$, et al. Aortic root dilatation as a cause of isolated, severe aortic regurgitation. Prevalence, clinical and echocardiographic patterns, and relation to left ventricular hypertrophy and function. Ann Intern Med. 1987; 106:800-7.

2. Gott VL, Gillinov AM, Pyeritz RE, Cameron DE, Reitz BA, Greene PS, et al. Aortic root replacement: risk factor analysis of a seventeenyear experience with 270 patients. J Thorac Cardiovasc Surg. 1995; 109:536-44.

3. Sarsam MA, Yacoub M. Remodeling of the aortic valve anulus J Thorac Cardiovasc Surg. 1993;105:435-8.

4. David TE, Feindel CM. An aortic valve-sparing operation for patients with aortic incompetence and aneurysm of the ascending aorta. $J$ Thorac Cardiovasc Surg. 1992;103:617-21.

5. De Paulis R, De Matteis GM, Nardi P, Scaffa R, Bassano C, Chiariello L. Analysis of valve motion after the reimplantation type of valvesparing procedure (David I) with a new aortic root conduit. Ann Thorac Surg. 2002;74:53-7.

6. Demers P, Miller DC. Simple modification of "T. David-V" valvesparing aortic root replacement to create graft pseudosinuses. Ann Thorac Surg. 2004;78:1479-81.

7. Aicher D, Langer F, Kissinger A, Lausberg H, Fries R, Schafers HJ. Valve-sparing aortic root replacement in bicuspid aortic valves: a reasonable option? J Thorac Cardiovasc Surg. 2004;128:662-8.

8. Schafers HJ, Aicher D, Langer F. Correction of leaflet prolapse in valve-preserving aortic replacement: pushing the limits? Ann Thorac Surg. 2002;74:S1762-4.

9. David TE. Surgery of the aortic valve. Curr Probl Surg. 1999;36:426501.

10. Schafers HJ, Bierbach B, Aicher D. A new approach to the assessment of aortic cusp geometry. J Thorac Cardiovasc Surg. 2006;132:436-8. 
11. Langer F, Aicher D, Kissinger A, Wendler O, Lausberg H, Fries R, et al. Aortic valve repair using a differentiated surgical strategy. Circulation. 2004;110(11 Suppl 1):II67-73.

12. Wilkenshoff UM, Kruck I, Gast D, Schroder R. Validity of continuous wave Doppler and colour Doppler in the assessment of aortic regurgitation. Eur Heart J. 1994;15:1227-34.

13. Luciani GB, Casali G, Tomezzoli A, Mazzucco A. Recurrence of aortic insufficiency after aortic root remodeling with valve preservation. Ann Thorac Surg. 1999;67:1849-52.

14. Leyh RG, Fischer S, Kallenbach K, Kofidis T, Pethig K, Harringer W, et al. High failure rate after valve-sparing aortic root replacement using the "remodeling technique" in acute type A aortic dissection. Circulation. 2002;106(12 Suppl 1):I229-33.

15. El Khoury GA, Underwood MJ, Glineur D, Derouck D, Dion RA. Reconstruction of the ascending aorta and aortic root: experience in 45 consecutive patients. Ann Thorac Surg. 2000;70:1246-50.

16. Yacoub M, Gehle P, Chandrasekaran V, Birks E, Child A, RadleySmith R. Late results of a valve-preserving operation in patients with aneurysms of the ascending aorta and root. J Thorac Cardiovasc Surg. 1998; $115: 1080-4$

17. Leyh RG, Schmidtke C, Sievers HH, Yacoub MH. Opening and closing characteristics of the aortic valve after different types of valve-preserving surgery. Circulation. 1999;100:2153-60.
18. Graeter TP, Fries R, Aicher D, Reul H, Schmitz C, Schafers HJ. In-vitro comparison of aortic valve hemodynamics between aortic root remodeling and aortic valve reimplantation. J Heart Valve Dis. 2006; 15:329-35.

19. David TE, Feindel CM, Webb GD, Colman JM, Armstrong S, Maganti $\mathrm{M}$. Long-term results of aortic valve-sparing operations for aortic root aneurysm. J Thorac Cardiovasc Surg. 2006;132:347-54.

20. de Oliveira NC, David TE, Ivanov J, Armstrong S, Eriksson MJ, Rakowski $\mathrm{H}$, et al. Results of surgery for aortic root aneurysm in patients with Marfan syndrome. J Thorac Cardiovasc Surg. 2003;125: 789-96.

21. Birks EJ, Webb C, Child A, Radley-Smith R, Yacoub MH. Early and long-term results of a valve-sparing operation for Marfan syndrome. Circulation. 1999;100(19 Suppl):II29-35.

22. Kallenbach K, Karck M, Pak D, Salcher R, Khaladj N, Leyh R, et al Decade of aortic valve sparing reimplantation: are we pushing the limits too far? Circulation. 2005;112(9 Suppl):I253-9.

23. Thubrikar MJ, Labrosse MR, Zehr KJ, Robicsek F, Gong GG, Fowler BL. Aortic root dilatation may alter the dimensions of the valve leaflets. Eur J Cardiothorac Surg. 2005;28:850-5.

24. Pethig K, Milz A, Hagl C, Harringer W, Haverich A. Aortic valve reimplantation in ascending aortic aneurysm: risk factors for early valve failure. Ann Thorac Surg. 2002;73:29-33. 